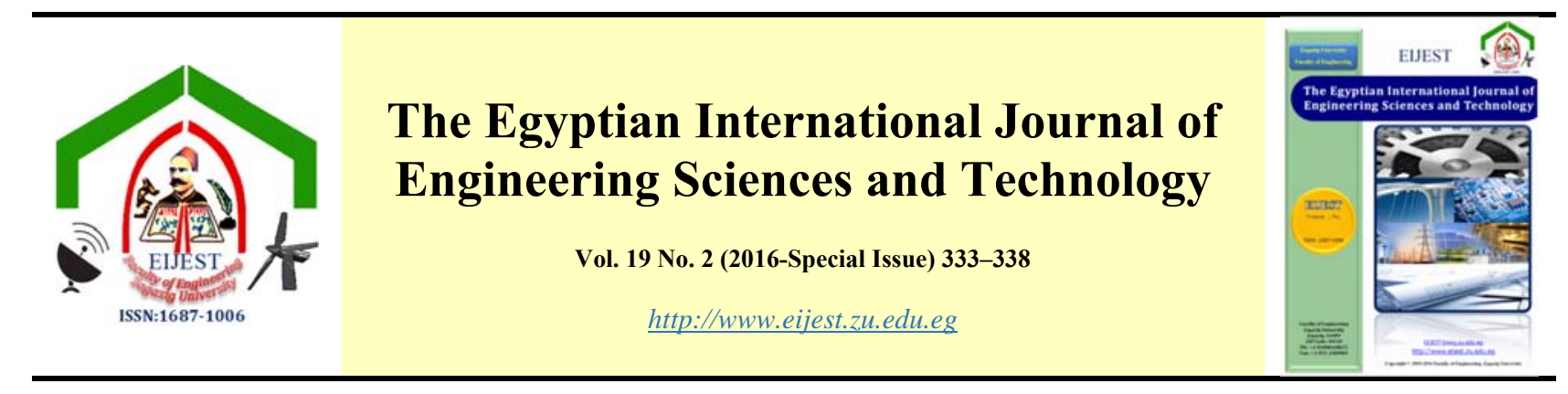

\title{
Geo-Spatial Tool for the Assessment Offshore Pile Driving Noise Effects on Marine Mammals
}

\author{
Waled Daoud ${ }^{a^{*}}$, Kiyonobu Kasama ${ }^{\mathrm{b}}$, Nasser Saleh ${ }^{\mathrm{c}}$, Abelazim Negm ${ }^{\mathrm{d}}$ and Mahmoud \\ Bady ${ }^{\mathrm{e}}$ \\ ${ }^{a, d, e}$ Egypt-Japan University of Science and Technology, Egypt (email: walid.dawoud@ejust.edu.eg) \\ ${ }^{a, b}$ Faculty of Engineering, Kyushu University, Japan \\ ${ }^{a, c}$ Faculty of Engineering at Shoubra, Benha University, Egypt
}

\begin{tabular}{l}
\hline A R T I C L E I N F O \\
\hline Article history: \\
Received 28 May 2016 \\
Accepted 22 June 2016 \\
Available online 1 July 2016 \\
\hline
\end{tabular}

\section{Keywords:}

Pile Driving Noise

Geospatial Assessment

Roger Model

Marine Mammals

Sound Exposure Level

\begin{abstract}
A B S T R A C T
Most of offshore structures are found on large diameter driven-piles that produce high amount of underwater noise that can propagate up to a distance of $200 \mathrm{~km}$. This underwater noise has detrimental effects on the marine mammals and at very high levels can injure or even kill the mammal. The propagation of underwater noise produced during pile driving is an important issue especially for newly constructed offshore structures. Geospatial tool to assess underwater noise propagation due to pile diving is proposed. The tool will serve to assess both Sound Exposure Level and Sound Pressure Level at any location. Pile Driven in the red sea near Jeddah Islamic Port was considered as a test case. The tool successfully predicted the underwater noise propagation at different locations. The accuracy of the tool depends mainly on the used prediction model, Roger's Model. Future updates will consider multiple piles driven at the same time and allow the user to use any other propagation model.
\end{abstract}

\section{Introduction}

Most of offshore structures are found on large diameter steel pipe piles that are driven into the seabed. During pile driving, high levels of underwater sound and pressure waves are produced that have detrimental effects on marine habitats. Field observations show peak acoustic pressures of $1.0 \mathrm{kPa}$ measured at a range of $3000 \mathrm{~m} \mathrm{[1]}$, around $10 \mathrm{kPa}$ measured at a range of $60 \mathrm{~m} \mathrm{[2],} \mathrm{and} \mathrm{around} 100 \mathrm{kPa}$ measured at a range of $10 \mathrm{~m} \mathrm{[3]} \mathrm{from} \mathrm{the} \mathrm{pile} \mathrm{driving}$ operation. Such pressures are known to produce deleterious effects on both fish and marine mammals [4].
Underwater noise effects on marine mammals are of particular interest because marine mammals has a wide distribution area in the coastal waters, acute hearing, and functional hearing over a very wide frequency range [5], [6], [7], [8]. Marine mammals are relatively easily deterred by anthropogenic underwater noises [9]. Avoidance threshold levels of harbor porpoises have been determined for noise bands and tonal signals around $12 \mathrm{kHz}$, a continuous $50 \mathrm{kHz}$ tone, and continuous and pulsed 70 and $120 \mathrm{kHz}$ tones [10]. Reference [9] studied the effects of underwater noise on marine mammals from driving $4.0 \mathrm{~m}$ diameter steel mono-pile foundations for offshore wind turbines in the North Sea (Source Level $235 \mathrm{~dB}$

\footnotetext{
* Corresponding author. Tel.: +2-010-1115-4974

E-mail address: walid.a.dawoud@gmail.com.
} 
re $1 \mu \mathrm{Pa}$ p-p at $1 \mathrm{~m})$, by quantifying their echo-location activity. Reduced echo-location activity occurred at over $21.0 \mathrm{~km}$ from the pile driving site. Reference [11] reported that offshore pile driving sounds reduced detected marine mammals acoustic signals at distances of up to $18 \mathrm{~km}$ from the sound source. Based on visual surveys and static acoustic monitoring; reference [12] reported strong avoidance within $20 \mathrm{~km}$, reduced echo-location at distances less than $11 \mathrm{~km}$, and increased detection rates at 25 and $50 \mathrm{~km}$ from the pile driving source.

Migration of underwater sound during pile driving is very important issue to assess the affected area and it is required by most regulations before work commencement [13], [14]. Threshold values of $160 \mathrm{~dB}$ for the sound exposure level (SEL) and 190dB for the peak SPL at a distance of $750 \mathrm{~m}$ from the pile were stated in German Regulation for newly constructed windfarms [15]. To comply with these regulations, accurate assessment of pile driving underwater noise migration is deemed necessary. Several analytical and numerical models were developed for this purpose. Thompson et al. [13] suggested the use of INSPIRE software based on hysteresis loss model. Lippert and Lippert [16] proposed the used of wave number integration. Both models are complex and need more efforts to produce clear results. This paper introduces the use of Rogers's wave propagation model combined with spatial analysis tool to predict underwater noise propagation due to pile driving. The tool was implemented in ArcGIS 10.2 to comply with The proposed tool aimed to simplify the process of underwater noise propagation yet with clear results.

\section{Underwater Noise}

\subsection{Pile driving underwater noise}

Four types of mechanical waves are produced during pile driving namely: Compressional, Shear, Rayleigh, and Lowe waves. Only compressional waves need to be considered when studying noise effects on marine mammals because its ability to travel in water [17]. Sound waves propagation in water differs than in air in many aspects; Sound waves in water have a pressure 60 times larger (and a displacement amplitude 60 times less) than that in the air because of the difference in acoustic impedance. Also the air/water interface acts as sound reflector (Lloyd's mirror) therefore sound generated underwater waves will not pass over the air and it will be reflected with an opposite polarity.

\subsection{Underwater Sound Propagation Models}

The understanding of underwater sound propagation is the key to understand and predict all other underwater acoustic phenomena. Different sound propagation models were developed since the world war II [18] which can be divided, based on its theoretical approach, as in Figure 2.

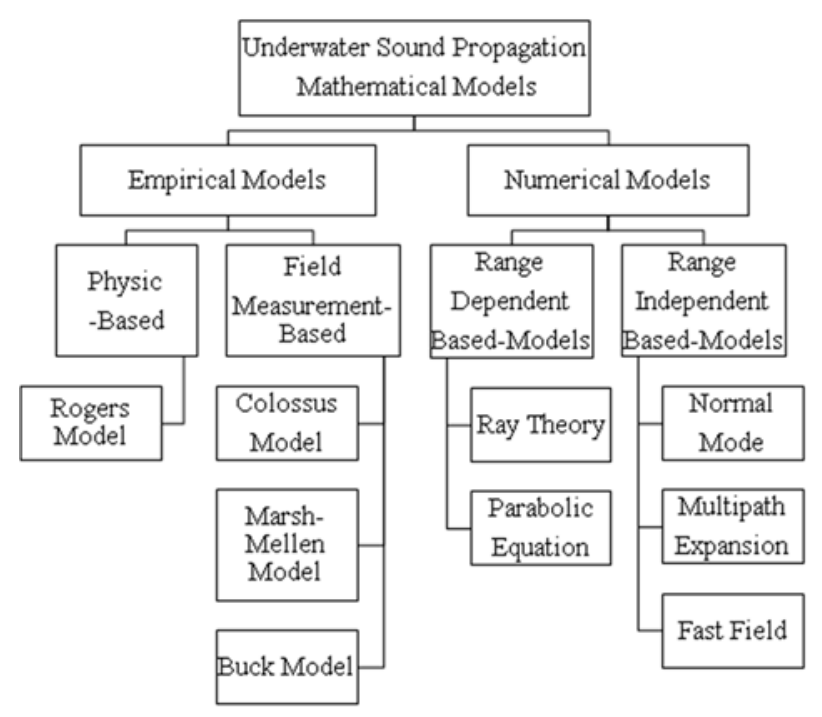

Fig. 1. Underwater Sound Propagation Models

Sound propagation model should take into account transmission losses (TL) of sound waves. The decay rate of sound waves propagate underwater depends mainly on sound frequency, sound source depth, water temperature, water salinity, water depth, and bottom conditions. The use of sophisticated models may lead to misleading results due to limited knowledge of subsurface conditions. Simplified empirical models can give a better estimate of the variation in sound wave with distance which is enough for the preliminary assessment of the pile driving noise on marine mammals.

\subsection{Rogers Model}

Rogers model was used to predict transmission losses underwater sound waves since 1981 [18]. The model was derived bases on theoretical approach (physics-based) assuming that all shallow water transmission losses, for negative sound speed gradient, can be described by the following equation:

$$
\begin{gathered}
T L=15 \log _{10}^{R}+5 \log _{10}^{(H \beta)}+\frac{\beta R \theta_{L}^{2}}{4 H}+ \\
\alpha_{w} R-7.18
\end{gathered}
$$


Where: $\mathrm{R}$ is the range $(\mathrm{m}) ; \mathrm{H}$ the water depth $(\mathrm{m}) ; \beta$ the bottom loss $\left(\mathrm{dB} \operatorname{rad}^{-1}\right) ; \theta_{\mathrm{L}}$ the limiting angle (rad); and $\alpha_{\mathrm{w}}$ the absorption coefficient of sea water

The bottom loss $\left(\beta \mathrm{dB} \operatorname{rad}^{-1}\right)$ can be approximated, for small limiting angles $\left(\theta_{\mathrm{L}}\right)$, as follows:

$$
\beta \approx \frac{0.477 M_{0} N_{0} k_{S}}{\left[1-N_{0}^{2}\right]^{3 / 2}}
$$

Where: $\mathrm{N}_{0}=\mathrm{c}_{\mathrm{w}} / \mathrm{c}_{\mathrm{s}}, \mathrm{c}_{\mathrm{w}}$ is the maximum (sea surface) sound speed $\left(\mathrm{ms}^{-1}\right) ; \mathrm{c}_{\mathrm{s}}$ is the sound speed $\left(\mathrm{ms}^{-1}\right)$ in the sediments; $M_{0}=\rho_{\mathrm{s}} / \rho_{\mathrm{w}}, \rho_{\mathrm{w}}$ is the density of sea water and $\rho_{\mathrm{s}}$ is the sediment density; and Ks is the sediment attenuation coefficient $\left(\mathrm{dB} \mathrm{m}^{-1} \mathrm{kHz}^{-1}\right)$

Numerous empirical methods, based on laboratory and field measurements, were developed to predict the sound speed in water. A simplified formula was given in [19] as follows:

$$
\begin{gathered}
C=1449.2+4.6 T-0.055 T^{2}+0.00029 T^{3} \\
+(1.34-0.01 T)(S-35)+0.016 H
\end{gathered}
$$

Where $\mathrm{T}$ is the temperature (oc); $\mathrm{S}$ is the salinity (PPT); and $\mathrm{H}$ is the depth (m).

\subsection{Noise effects on marine mammals}

The potential for underwater noise to affect marine mammals depends on how well the animal can hear the noise. Noises which can't be heard well by the mammal are less likely to disturb or injure them except when it is associated with high sound pressure that can causes physical injury [20]. Marine mammals can be divided based on its functional hearing to the groups shown in Table I [20]:

Table 1. Functional hearing groups

\begin{tabular}{lc}
\hline Functional hearing group & $\begin{array}{c}\text { Estimated auditory } \\
\text { bandwidth }(\mathrm{kHz})\end{array}$ \\
\hline Low-frequency cetaceans & $0.007-22$ \\
Mid-frequency cetaceans & $0.150-160$ \\
High-frequency cetaceans & $0.200-180$ \\
Pinnipeds in water & $0.075-75$ \\
Pinnipeds in air & $0.075-30$ \\
\hline
\end{tabular}

Marine mammals have different hearing at different frequencies within their functional hearing range; frequency weighting is used to quantitatively compensating for the difference in frequency response based on mammal's audiograms [21]. Two metrics are commonly used to describe sound parameters: sound pressure level (SPL) and sound exposure level (SEL). SPL is the maximum sound pressure at any given moment produced by a particular activity measured in $\mathrm{dB}$ re: $1 \mu \mathrm{Pa}$. SEL is a measure of energy exposure level measured in $\mathrm{dB}$ re: $1 \mu \mathrm{Pa}^{2} \mathrm{~s}$.

To assess the impact of underwater noise marine mammals, the marine mammals were divided into three main categories; Dolphins Whales, and Dugongs. The SEL threshold levels (in $\mathrm{dB}$ re: $1 \mu \mathrm{Pa} 2 \mathrm{~s}$ ) for these categories are as shown in Table 2 [21]:

Table 2. Estimated impact SEL thresholds

\begin{tabular}{lccc}
\hline Species & $\begin{array}{c}\text { Permanent } \\
\text { Threshold } \\
\text { Shift }\end{array}$ & $\begin{array}{c}\text { Temporary } \\
\text { Threshold } \\
\text { Shift }\end{array}$ & $\begin{array}{c}\text { Behavioral } \\
\text { Response }\end{array}$ \\
\hline Dolphins & $>178-198$ & $>183$ & $>120-150$ \\
Whales & $>178-198$ & $>183$ & $>120-180$ \\
Dugongs & $>178-198$ & $>183$ & $>120-150$ \\
\hline
\end{tabular}

\section{GEOSPATIAL ASSESSMENT TOOL}

\subsection{Assessment Procedures}

The assessment procedures that were implemented in the Geospatial tool can be summarized as follows:

1. All Input data are collected into single folder. The needed input data are: seabed bathymetry, salinity, temperature, pile location, driving energy, sound amplitude, and sound pressure.

2. The tool estimate both SEL and SPL based on the input data. Also transmission losses are estimated.

3. Spatial distribution of the estimated values.

4. Based on the type of mammal, marine mammal's exposure level contours are generated, based on Table 2.

\subsection{Layers and Tables}

The geospatial tool uses several layers and tables for input, processing, and output. Main layers are shown in Table 3:

Table 3. Geospatial Tool Layers

\begin{tabular}{lll}
\hline Layer Name & Type & Description \\
\hline SeaBedBath. & Raster Data & Bathymetry \\
SeaSalinity & Point Data & Salinity \\
SeaTemp & Raster Data & Temperature \\
\hline
\end{tabular}




\begin{tabular}{lll}
\hline PileLocat & Point Data & Pile Location \\
HamEnergy & Input Value & Driving Energy \\
Samplitude & Input Value & Sound Amplitude \\
SPressure & Input Value & Sound Pressure \\
InitSPL & Raster Data & Initial SPL \\
InitSEL & Raster Data & Initial SEL \\
TL & Raster Data & Transmission \\
FinalSPL & Raster Data & Final SPL \\
FinalSEL & Raster Data & Final SEL \\
\hline
\end{tabular}

\section{TEST CASE: PILE DRIVING IN THE RED- SEA}

\subsection{Input Data}

The red sea bathymetry was attained from National Oceanic and Atmospheric administration [22] with 4 $\mathrm{km}$ resolution. The data then resampled into $1.0 \mathrm{~km}$ resolution using beam bathymetry survey data attained from [23] as shown in Figure 2. The salinity and temperature data in Red Sea were extracted from [22]. The average salinity in the red sea was $41.2 \mathrm{psu}$ and average water temperature was $22.5^{\circ} \mathrm{C}$.

The study was made to be consistent with one of the 136 piles constructed near the west coast of Saudi Arabia; a hollow steel pile, approximately $96 \mathrm{~m}$ long with $1.40 \mathrm{~m}$ diameter and wall thickness of $1.9 \mathrm{~cm}$. The pile was driven approximately $80 \mathrm{~m}$ into the sediment in water $16.0 \mathrm{~m}$ deep [24]. The piles were driven with a Kobe-80 Diesel Hammer with ram weight of $78.5 \mathrm{kN}$ and energy of $235 \mathrm{~kJ}$. No cushion between the ram and pile was used. The sound source level from the $235 \mathrm{~kJ}$ hammer was predicted by assuming the underwater noise output of a pile strike is proportional to the energy delivered to the pile as in (4):

$$
\Delta B_{0}=10 \log _{10}\left(\frac{E}{E r}\right)
$$

The reference sound source level was for the $49 \mathrm{~kJ}$ diesel hammer proposed in [21]. Table 4 shows the reference source levels and the predicted source levels for the $235 \mathrm{~kJ}$ hammer.

Table 4. Reference and predicted source levels (at $1.0 \mathrm{~m}$ )

\begin{tabular}{ccc}
\hline $\begin{array}{c}\text { Hammer } \\
\text { Energy }\end{array}$ & SEL & SPL \\
(dB re $1 \mu P a 2 . s)$ & $(d B$ re $1 \mu P a)$ \\
\hline $49 \mathrm{~kJ}$ & 199 & 213 \\
$235 \mathrm{~kJ}$ & 205.8 & 219.8 \\
\hline
\end{tabular}

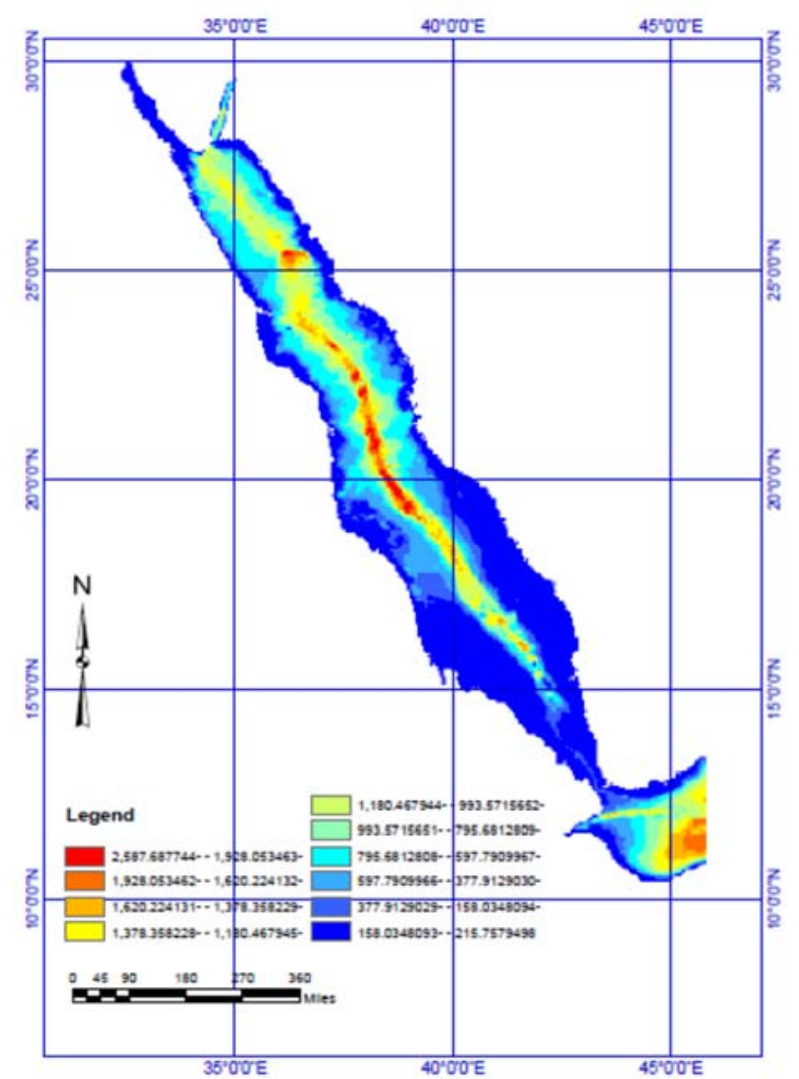

Fig. 2. Red sea bathymetry

\subsection{SEL Prediction}

The transmission losses (TL) were calculated at each point using equations 1 to 3 . Sound Exposure level is then calculated using the following formulae:

$$
S E L_{i}=S E L_{o}-T L_{i}
$$

Where: SELi is the sound exposure level at point $i$; SELo is the sound exposure level at source; and TLi is the transmission losses at point $\mathrm{i}$.

\subsection{Outputs}

The spatial distribution of underwater noise propagation due to pile driving is shown in Figure 3. Figure 3.a shows the distribution of Sound Exposure Level around the piles, Figure 3.b shows those for Sound Pressure Level. It can be seen that the underwater noise from pile driving in the Red Sea can propagate to a distance of $100 \mathrm{~km}$. Summary of the main results are shown in Table 5. 

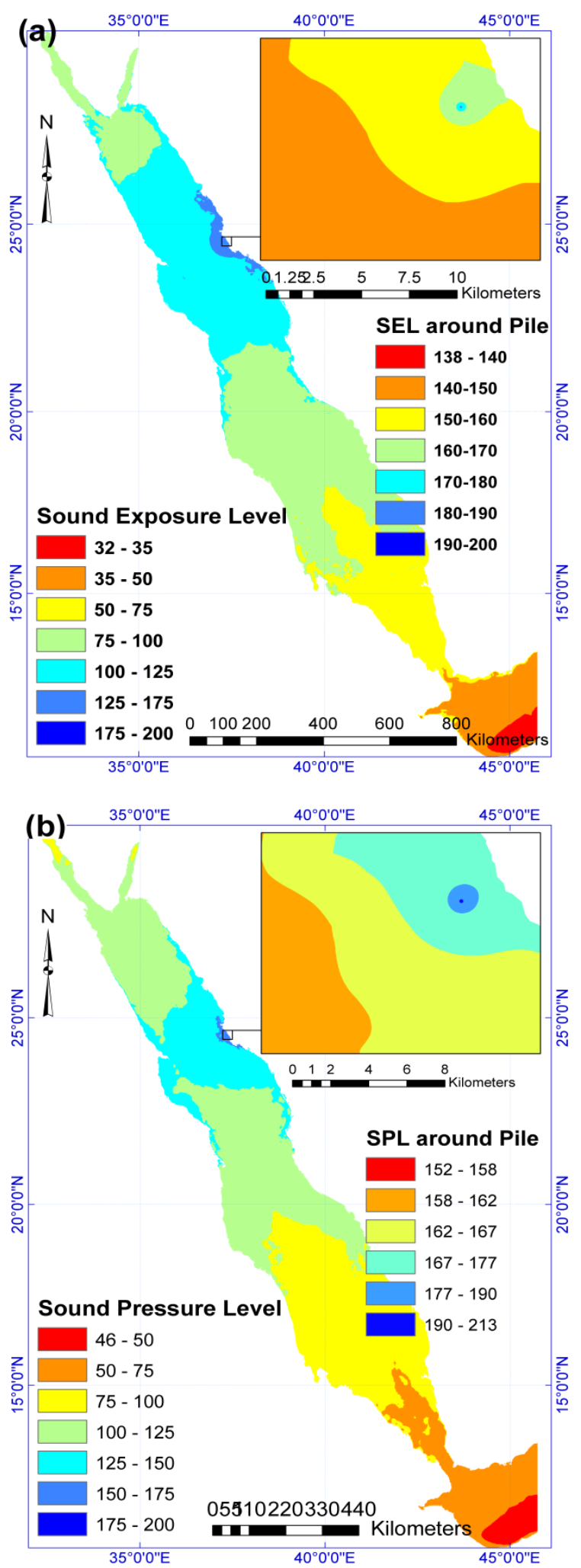

Fig. 3. Predicted underwater noise propagation. (a) SEL and (b) SPL
Table 5. SEL radii for a single impact pile driving strike (320 kJ)

\begin{tabular}{ccc}
\hline $\begin{array}{c}\text { SEL Threshold } \\
\left(\mathrm{dB} \mathrm{re} 1 \mu \mathrm{Pa}^{2} \cdot \mathrm{s}\right)\end{array}$ & $\begin{array}{c}\text { R95\% } \\
(\mathrm{km})\end{array}$ & $\begin{array}{c}\text { REA } \\
(\mathrm{km})\end{array}$ \\
\hline 190 & 0 & 0 \\
180 & 0.011 & $<0.028$ \\
170 & 0.21 & 0.19 \\
160 & 0.79 & 0.71 \\
150 & 4.4 & 2.5 \\
140 & 14 & 6.9 \\
\hline
\end{tabular}

\section{DISCUSSION}

Geospatial tool implemented in ArcGIS 10.2 was proposed to predict underwater noise propagation due to pile driving. The sound propagation was predicted based on Rogers's model. The tool will serve different discipline to estimate the sound level at specific location. Underwater noise due to pile driving noise in the red sea was used as a test case. The case showed that the tool is powerful enough to estimate both sound exposure level and sound pressure level at any location. The tool has also the capability to predict underwater noise for multiple piles driven at the same time.

The accuracy of the predicted results depends mainly on the accuracy of the used model, Rogers's Model. Verification of the predicted results using field measurements will strength the tool and make it more credible. Future updates in the tool will consider multiple piles driven at the same time and allow the user to use any other propagation model.

\section{ACKNOWLEDGMENTS}

W. A. Daoud is thankful to the Egyptian Ministry of Higher Education (MoHE) for funding his $\mathrm{PhD}$ studies as a scholarship. Also great thanking is due to Egypt-Japan University of Science and Technology (E-JUST) for offering the tools and equipment needed for the research. 


\section{REFERENCES}

[1] C. A. f De Jong and M. A. Ainslie, "Underwater radiated noise due to the piling for the Q7 Offshore Wind Park," J. Acoust. Soc. Am., vol. 123, no. 5, p. 2987, 2008.

[2] S. P. Robinson, P. A. Lepper, and J. Ablitt, "The measurement of the underwater radiated noise from marine piling including characterisation of a 'soft start' period," in OCEANS 2007 Europe, 2007, pp. 1-6.

[3] P. Dahl, "An Investigation of Underwater Sound Propagation from Pile Driving," wsdot.wa.gov, 2011.

[4] P. T. Madsen, M. Wahlberg, J. Tougaard, K. Lucke, and P. Tyack, "Wind turbine underwater noise and marine mammals: implications of current knowledge and data needs," Mar. Ecol. Prog. Ser., vol. 309, pp. 279-295, Mar. 2006.

[5] R. A. Kastelein, P. Bunskoek, M. Hagedoorn, W. W. L. Au, and D. de Haan, "Audiogram of a harbor porpoise (Phocoena phocoena) measured with narrow-band frequency-modulated signals," J. Acoust. Soc. Am., vol. 112, no. 1, p. 334, 2002.

[6] R. A. Kastelein, P. J. Wensveen, L. Hoek, W. W. L. Au, J. M. Terhune, and C. A. F. de Jong, "Critical ratios in harbor porpoises (Phocoena phocoena) for tonal signals between 0.315 and $150 \mathrm{kHz}$ in random Gaussian white noise.," J Acoust. Soc. Am., vol. 126, no. 3, p. 1588, Sep. 2009.

[7] R. A. Kastelein, L. Hoek, C. A. F. de Jong, and P. J. Wensveen, "The effect of signal duration on the underwater detection thresholds of a harbor porpoise (Phocoena phocoena) for single frequency-modulated tonal signals between 0.25 and 160 kHz.," J. Acoust. Soc. Am., vol. 128, no. 5, pp. 3211-22, Nov. 2010

[8] R. A. Kastelein, N. Steen, C. de Jong, P. J. Wensveen, and W C. Verboom, "Effect of broadband-noise masking on the behavioral response of a harbor porpoise (Phocoena phocoena) to 1-s duration 6-7 kHz sonar up-sweeps.," J. Acoust. Soc. Am., vol. 129, no. 4, pp. 2307-15, Apr. 2011

[9] J. Tougaard, J. Carstensen, J. Teilmann, H. Skov, and P. Rasmussen, "Pile driving zone of responsiveness extends beyond $20 \mathrm{~km}$ for harbor porpoises (Phocoena phocoena (L.)).," J. Acoust. Soc. Am., vol. 126, no. 1, pp. 11-4, Jul. 2009.

[10] J. Carstensen, O. D. Henriksen, and J. Teilmann, "Impacts of offshore wind farm construction on harbour porpoises: acoustic monitoring of echolocation activity using porpoise detectors (T-PODs)," Mar. Ecol. Prog. Ser., vol. 321, pp. 295308, 2006.

[11] M. J. Brandt, A. Diederichs, K. Betke, and G. Nehls, "Responses of harbour porpoises to pile driving at the Horns Rev II offshore wind farm in the Danish North Sea," Mar. Ecol. Prog. Ser., vol. 421, pp. 205-216, 2011
[12] M. Dähne, A. Gilles, K. Lucke, V. Peschko, S. Adler, K. Krügel, J. Sundermeyer, and U. Siebert, "Effects of piledriving on harbour porpoises (Phocoena phocoena) at the first offshore wind farm in Germany," Environ. Res. Lett., vol. 8, no. 2 , p. 25002,2013

[13] P. M. Thompson, G. D. Hastie, J. Nedwell, R. Barham, K. L. Brookes, L. S. Cordes, H. Bailey, and N. McLean, "Framework for assessing impacts of pile-driving noise from offshore wind farm construction on a harbour seal population," Environ. Impact Assess. Rev., vol. 43, pp. 73-85, Nov. 2013.

[14] A. Tsouvalas and A. V. V. Metrikine, "A semi-analytical model for the prediction of underwater noise from offshore pile driving," J. Sound Vib., vol. 332, no. 13, pp. 3232-3257, Jun. 2013.

[15] "Leits $\{\ddot{a}\}$ tze $\mathrm{f}\{\ddot{\mathrm{u}}\} \mathrm{r}$ die Anwendung der Eingriffsregelung innerhalb der ausschlie $\{\beta\}$ lichen Wirtschaftszone und auf dem Festlandsockel im Rahmen von $\{\backslash \mathrm{S}\}$."

[16] T. Lippert and S. Lippert, "Modelling of pile driving noise by means of wavenumber integration," Acoust. Aust., vol. 40, no. 3 , p. 179,2012 .

[17] I. A. of O. and G. Producers and R. No, "Fundamentals of underwater sound," 2008.

[18] P. C. Etter, Underwater Acoustic Modeling and Simulation. Abingdon, UK: Taylor \& Francis, 2003.

[19] H. Medwin and C. Clay, Fundamentals of acoustical oceanography. 1998.

[20] B. Southall, A. Bowles, and W. Ellison, "Marine mammal noise-exposure criteria: initial scientific recommendations," Bioacoustics, vol. 33, no. 4, 2008.

21] P. Hedland, C. P. S. Kent, R. D. Mccauley, and A. J. Duncan, "Environmental impacts of underwater noise associated with harbour works," 2009.

[22] N. G. D. Center, "Multibeam Bathymetric Data ngdc.noaa.gov."

[23] "Marine Environmental Data." [Online]. Available: http://www.niwa.co.nz/ourscience/oceans/bathymetry/download-the-data. [Accessed: 29-Oct-2014]

[24] W. Akili, "Pile Driving in Coral Deposits: A Case Study along the Red Sea," Geotech. Spec. Publ., pp. 604-618, 2002. 